\title{
Research on Human Subjectivity and Environmental Integrity in Modern Interior Design
}

\author{
Yin Lu \\ College of Fine Arts, Hubei Normal University, Huangshi, Hubei, 435002, China
}

Keywords: Modern Interior Design; Human Subjectivity; Environmental Integrity

\begin{abstract}
The rapid development of the construction industry has promoted the improvement of modern interior design and it has become an important work to ensure people's living conditions. After a construction project is completed, perfect interior design is needed to deepen the architectural design space, with the purpose to enhance people's basic living experience and realize the expansion of architectural functions. In the process of development, modern interior design gives full play to the people-oriented concept and pays attention to people's subjectivity. At the same time, the integrity of the environment should also be fully considered, so as to realize the effective combination of the two and enhance the effect of architectural interior design. By analyzing the basic connotation of human subjectivity and environmental integrity in modern interior design, this paper explored the design strategy of human subjectivity and environmental integrity in modern interior design.
\end{abstract}

\section{Introduction}

In recent years, the scale of construction projects is gradually expanding, and the types of buildings are constantly enriching, providing a strong guarantee for people's life, work and study. People's demand for building functions is also gradually increasing, especially for building interior design. Only by improving the quality of interior design can designers create a comfortable environment for people's living and improve their quality of life. In modern interior design, designers should comprehensively consider the subjectivity of people and the integrity of the environment, realize the overall coordination among architecture, people and the environment, and truly implement the people-oriented design concept. Therefore, in addition to improving the level of modern interior design technology, attention should be paid to the quality of interior design materials, energy conservation and environmental protection in the design process, so as to lay a foundation for the improvement of people's living condition in the future. The human subjectivity should be embodied by satisfying material needs, spiritual needs and psychological needs in the design; the environmental integrity should be embodied in the space sequence relationship, decoration style and space.

\section{The basic connotation of human subjectivity and environmental integrity in modern interior design}

\subsection{The basic connotation of human subjectivity in modern interior design}

The embodiment of human subjectivity in modern interior design should focus on meeting the needs of human and interpersonal activities. It is people who are users of architecture, so interior design should always put people's needs and feelings first to meet their material needs, spiritual needs and psychological needs. The work of modern interior design is complicated. Only by adhering to the people-oriented design concept can designers sort out the clue for the development of the work, standardize the interior design process under the guidance of the basic concept and design concept, and ensure the comfort of people living. In the process of modern construction, more and more attention has been given to human subjectivity, which is also a key link in promoting the construction industry and the level of modern interior design. 


\subsection{The basic connotation of environmental integrity in modern interior design}

The environmental integrity is also an important consideration in modern interior design. The integrity of the environment needs to be reflected in the environment atmosphere, interior style, design conception and conception. It should also pay more attention to the overall coordination between the indoor environment and the outdoor environment. However, in the current modern interior design, there is low emphasis on environmental integrity, and most of ideas for design lack creativity and cannot meet people's requirements for the environment. Indoor space environment also includes psychological environment and physical environment; air quality environment, space environment, visual environment and the environment of sound, light and temperature belong to the category of physical environment [1]. In the process of indoor environment design, in order to better reflect the overall characteristics, attention should also be given to the improvement of psychological environment and air quality environment while the basic need for proper acoustical, visual and thermal environment is on the schedule. In addition, the integrity of the indoor design environment should focus not only on the indoor environment, but also on the coordination of the indoor environment with the outdoor environment and the natural environment.

\section{The design strategy of human subjectivity and environmental integrity in modern interior design}

\subsection{The design principles of human subjectivity and environmental integrity in modern interior design}

\subsubsection{Meeting people's material needs}

Modern interior design should fully embody the people-oriented design concept and show concern for people in the design. The use function of a building is mainly reflected in the interior space, and the quality of the modern interior design is reflected in people's feelings about the design elements. To embody human subjectivity in modern interior design lies in satisfying people's material needs. Modern interior design should meet people's demand for space functions. The interior space of buildings is different from natural space. The natural space is infinite while the building interior space belongs to man-made space, and thus the function of the building interior space should be maximized in man-made design to improve people's living comfort. People's different feelings for the interior space of the building stem from the difference of designers' design ideas for the space form. The rational design of the relationship between height, dimension and shape of indoor space is the key work to meet people's need for space functions in modern indoor design [2]. Public buildings and residential buildings also differ in space design. Public buildings require more space and need to be able to give people a sense of grandeur; residential buildings, especially bedrooms, require less space and are expected to make people feel warm and comfortable. In modern interior design, the control of the height should be started from two aspects, namely relative height and absolute height. The design of absolute height cannot be too high or too low, because an absolute height too high can make people feel empty and too low can make people feel depressed. Therefore, modern interior designers should effectively grasp the relative height and absolute height to control the height at the most comfortable ratio. The effective division of psychological space, physiological space and behavioral space through the rational design of interior space can meet the needs of different people for interior space and fully respect the subjectivity of human.

\subsubsection{Meeting people's spiritual needs}

The construction purpose of buildings is to be used by people. Only by fully satisfying people's spiritual needs in modern interior design can buildings create a good environment for people's living, which is also a key way to reflect the subjectivity of human and integrity of the environment. Especially under the situation that the social rhythm is gradually accelerating, people are facing tremendous pressure of life and work every day. Whether it is the design of office environment or 
living environment, it will play an important role in relieving people's pressure if people can feel the spiritual pleasure brought by the environment. In a comfortable environment, people's spirit can be more relaxed, thus obtaining a higher quality of life.

\subsection{The design measures of human subjectivity and environmental integrity in modern interior design}

\subsubsection{Conforming to the principle of ergonomics}

People's activities in a building are always connected with the interior space of the building. In the past architectural interior design, there was often a lack of understanding of ergonomics, resulting in the interior space not conforming to the principles of ergonomics; the design work carried out based on experience could not reflect the subjectivity of human, reducing the comfort of people living [3]. Therefore, designers should apply scientific methods and fully consider the requirements of ergonomics in modern interior design, so as to meet the needs of human activities for space. Human body measurement, psychological measurement and physiological measurement should be used to study the function, mechanics and psychology of human body structure, with the purpose to ensure the balance and coordination between human and interior design. This can improve the use effect of the building and also the comfort, safety and health of the indoor space of the building.

Human sense organs and locomotive organs play a major role in the process of interacting with indoor space. In modern interior design, designers should take into account factors such as human body size, activity ability, human posture and distance between human and space, realizing the mutual coordination between the architectural interior space and human's movement characteristics, shape characteristics and physical fitness. The construction of indoor environment is the most important link in the combination of modern indoor design and ergonomic principles. This is because people's vision is most sensitive to the perception of the environment. Only by ensuring the beauty of the indoor environment can the indoor environment of a building offer comfortable visual enjoyment and enhance people's living experience. Therefore, the influence of humidity, sound, temperature, light, color and other factors on people's feeling and perception should be considered in modern interior design. In particular, color has significant impacts on people's vision, because reasonable and scientific color matching can make people happy physically and mentally, while unreasonable color matching often brings negative emotions to people.

\subsubsection{Paying attention to the design of light environment}

The design of light environment is a key link to ensure the environmental integrity in modern interior design. In modern interior design, light not only reflects its practicality, but also shows the cultural distinctiveness of the design. It plays an important role in separating the space, defining the space and changing the sense of space. Besides, it can well embody the decoration content, cultural connotation and space style of the building interior. Therefore, in addition to meeting the basic need for lighting intensity, the design of light environment should also focus on the flexible use of light to create a comfortable environment for people's living and reflect the integrity of the environment.

First of all, it is needed to lay stress on the design of natural light environment. Due to the accelerated pace of people's life, the distance between human beings and nature is getting farther and farther, generating increasing high desire of people for nature. The emphasis on the natural light environment in modern interior design can meet people's demand for nature and relieve their pressure of work and life. This requires modern interior designers to make full use of natural light to achieve harmony and balance with the overall environment of the building. The diversity of natural light changes lays a foundation for enriching the indoor environment, so designers should pay more attention to the physiological effects on people in natural light environment design [4]. In the design of natural light environment, attention should be paid to the coordination of light and shadow. While increasing the space movement, it is also necessary to improve the texture of interior decoration materials. People's demand for lighting function of natural light is low, but they keep higher demand for natural light to enhance indoor environment and meet their psychological needs. The reasonable 
design of natural light can simultaneously reflect the human subjectivity and environmental integrity, thereby helping people live comfortably. It is necessary to attach importance to the relationship between architectural entity and light and shadow, strengthen the interaction between natural light and space composition, and create an indoor space full of artistic charm. Advanced science and technology can make the introduction of natural light more sufficient and reasonable, and thereby effectively meet people's demand for natural light.

Secondly, attention should be given to the design of artificial light environment. The improvement of people's requirements for indoor environment makes the design of artificial light environment more difficult. Designers should ensure the depth and breadth in the design of artificial light environment to meet the basic lighting requirements and realize the adjustment and improvement of the indoor environment. At the same time, it is necessary to reasonably divide the relevant areas, control the sense of objects' size and weight, and effectively adjust the lightness, hue and purity of colors. The artificial light environment has strong controllability. Therefore, the design of artificial light environment can create a specific atmosphere and emotional appeal in the indoor space to highlight the artistic conception of the indoor environment and meet people's spiritual needs.

\subsubsection{Attaching importance to the design of color environment}

Reasonable color design and matching can create different indoor environments for people and meet the different needs of different groups of people for indoor environments. In the design, the flexibility and variability of colors should be guaranteed to meet the different needs for the indoor environment and improve the visual coordination. For example, it is necessary to reflect the grandeur of the place in the color design of the hotel lobby, office space and shopping place. This requires the application of colorless or gray tone (pure gray, gray, white or partial black, etc.) to reflect the characteristics of coolness and simplicity. The area with strong color blocks should not be too large, so as to ensure that it is easy to replace and concise. In addition, attention should also be given to the decorative design of colors. Reasonable color design can beautify the interior space and environment of the building, transfer emotion and culture and embody the symbolic meaning of color. For example, some colors have local, national and religious significance, and the combination of color design and emotional elements can promote the interaction between people and the environment [5].

\subsubsection{Laying stress on the design of material texture}

In order to improve the overall effect of interior design, it is necessary to effectively select and design interior materials. Different decorative materials used indoors can lead to obvious differences in people's psychology, vision and emotion; furthermore, the combination of light environment and color environment can improve the quality of interior design and highlight the human subjectivity and environmental integrity. The combination of different texture materials in the indoor floor decoration can realize the functions of dividing space, highlighting conception, setting off the environment and changing vision. In the process of design, designers should highlight the theme of interior design according to different material implications, maintain the unity of material implications and characteristics, which will play a key role in setting off the overall interior environment. Keeping the difference of materials in their meaning and forms can reflect the artistic aesthetics in design, displaying the charm of design in the strong conflict impact.

\section{Conclusions}

Scientific and reasonable modern interior design can improve people's living quality and meet the needs of different groups of people for living environment. In the process of interior design, it is necessary to meet the material and spiritual needs of human beings in order to highlight the subjectivity of human beings and the integrity of the environment. The design effect can be improved through the design of light environment, space, color environment and interface materials. Architecture itself serves human beings, so focusing on the coordination between human 
subjectivity and environmental integrity is an important way to implement the people-oriented design concept.

\section{References}

[1] Xie Nan, Fan Yipeng. On Human Subjectivity and Environmental Integrity in Modern Interior Design [J/OL]. Henan Building Materials, 2018 (05): 423-424.

[2] Guang Ningqiang. Discussion on Environmental Psychology and Modern Interior Design [J]. Sichuan Cement, 2015 (04): 164.

[3] Yan Jun, Ge Hanqing. Environmental Psychology and Modern Interior Design [J]. Art and Technology, 2013, 26 (01): 157.

[4] Ou Chaohai, Liu Xiaopei. On Environmental Psychology and Modern Interior Design [J]. Industrial Architecture, 2007 (S1): 1-3.

[5] Yin Sijin. Human, Emotion, Environment and Modern Interior Design (3) -- Light Environment, Color Environment and Quality Environment Design [J]. Interior Design Construction, 1995 (03): 8-13. 